\title{
Measurement of Left Ventricular Ejection Fraction in Pediatric Patients Using the Nuclear Stethoscope
}

\author{
ROBERT L. SPICER, MD, MARK RABINOVITCH, MD, AMNON ROSENTHAL, MD, \\ and BERTRAM PITT, MD
}

Left ventricular (LV) ejection fraction (EF) was measured in 25 patients, aged 2 weeks to 20 years (mean 8.6 years), using a portable nonimaging scintillation stethoscope. Technically satisfactory studies were obtalned in 23 patlents. LVEF was validated by cineangiography in 19 patients and by standard gated blood pool scintigraphy in 4 . EF measured by the nuclear stethoscope correlated well with values obtained by cineangiography or scintigraphy $(r=0.869, p<0.001)$ over a wide range of $E F$ values ( 18 to $79 \%$ ). In children younger than 5 years $(n=11)$, the correlation $(r=0.728$, $p$ $<0.02$ ) was less satisfactory than in those older than 5 years $(r=0.926 ; p<0.001)$. Although modifications in the instrument and further clinical trials with the stethoscope are needed before the device becomes clinically useful to pediatric cardiologists, our data indicate that the nuclear stethoscope can provide reliable assessment of LVEF in pediatric patients.

(Am J Cardiol 1984;53:211-214)
Recent advances in radiopharmaceuticals, imaging systems and computer capabilities have allowed application of many nuclear cardiology techniques to pediatric patients. Radionuclide angiography has been applied to left and right ventricular function analysis in children with structurally normal hearts and those with congenital defects. ${ }^{1-5}$ Since the first report on the use of a nonimaging scintillation probe to develop left ventricular $(\mathrm{LV})$ time-activity curves in $1976,{ }^{6}$ the nuclear stethoscope has been shown to determine $\mathrm{LV}$ ejection fraction (EF) accurately at rest ${ }^{7,8}$ and with exercise $^{9}$ in the normal ${ }^{8,9}$ and abnormal ${ }^{7-11}$ heart. The present study determines the accuracy and utility of the nuclear stethoscope in assessing LVEF in children and adolescents with cardiovascular disease.

\section{Methods}

Patients: Twenty-five patients, aged 2 weeks to 20 years (mean 8.6 years), with a variety of congenital and acquired cardiac defects were studied with the nuclear stethoscope (Table I). Among the group with congenital defects, 11 had prior palliative or corrective surgery for the defect and $10 \mathrm{had}$ no prior cardiac surgery. Twenty-one patients were studied during cardiac catheterization and LV cineangiography was

From the Division of Pediatric Cardiology, C.S. Mott Children's Hospital, Department of Pediatrics, and the Divisions of Nuclear Medicine and Cardiology, Department of Internal Medicine, University of Michigan Medical Center, Ann Arbor, Michigan. Manuscript received June 6 , 1983; revised manuscript received September 26, 1983, accepted September 27, 1983.

Address for reprints: Amnon Rosenthal, MD, F1123, Box 66, University of Michigan Medical Center, Ann Arbor, Michigan 48109. performed in each. In 4 patients studied on the ward or intensive care unit, a standard gated blood pool acquisition scintigraphy was performed. Two of 21 patients catheterized were excluded because of technical difficulties in achieving red blood cell labeling with the radiopharmaceutical. The 23 patients with adequate stethoscope studies and either scintigraphic $(n=4)$ or angiographic studies $(n=19)$ comprise the study group.

Radionuclide imaging technique: All patients underwent in vivo red blood cell labeling using i.v. stannous pyrophosphate $(10 \mu \mathrm{g} \mathrm{Sn}+2 / \mathrm{kg})$ followed 15 to 20 minutes later by the administration of technetium $-99 \mathrm{~m}$ pertechnetate. The dose of technetium was calculated using a body surface nomogram adjusting the adult dose of $20 \mathrm{mCi} / 1.7 \mathrm{~m}^{2}$ to the child's body surface area. The commercially available computerized nuclear probe (Nuclear Stethoscope ${ }^{\circledR}$, Bios) was used for all studies. The probe device, which has been described extensively in previous reports, ${ }^{7,9}$ consists of a 2 -inch sodium iodide crystal detector with a microcomputer which measures and displays a high temporal resolution $(10 \mathrm{~ms})$ image of the LV time-activity curve. The position/monitor mode of the device displays beat-to-beat time-activity curves and allows localization of the optimal LV and background positions with a series of computer-assisted algorithms. Using the positionmonitor mode of the stethoscope, 10 to 20 consecutive cardiac cycles were identified using manually controlled cursors and then analyzed by the microprocessor. The microprocessor determination of ejection fraction was made using the formula (end-diastolic counts - end-systolic counts)/(end-diastolic counts - background counts).

The 4 patients studied using gated blood pool techniques were imaged using a computerized single-crystal scintillation camera (Technicare Sigma $420^{(\mathcal{B})}$. $\mathrm{EF}^{\mathrm{F}}$ was calculated by an 
TABLE I Cardiac Diagnoses in 25 Children with Nuclear Stethoscope Studies

\begin{tabular}{|c|c|c|}
\hline \multicolumn{3}{|l|}{ Congenital heart defects $(n=21)$} \\
\hline Nonoperated & & 10 \\
\hline Ventricular septal defect & 3 & \\
\hline Pulmonary valve stenosis & 2 & \\
\hline Cardiomyopathy & 2 & \\
\hline Tetralogy of Fallot & 1 & \\
\hline Mitral incompetence & 1 & \\
\hline Endocardial cushion defect & 1 & \\
\hline Postoperative & & 11 \\
\hline Repaired & & \\
\hline Tetralogy of Fallot & 2 & \\
\hline Endocardial cushion defect & 2 & \\
\hline $\begin{array}{l}\text { Ebstein's anomaly } s / p \text { tricuspid } \\
\text { valve replacement }\end{array}$ & 2 & \\
\hline Ventricular septal defect & 1 & \\
\hline Total anomalous pulmonary venous return & 1 & \\
\hline Tricuspid atresia s/p Fontan & 1 & \\
\hline Aortic stenosis $s / p$ valvotomy & 1 & \\
\hline Palliated & & \\
\hline Tricuspid atresia s/p aortopulmonary shunt & 1 & \\
\hline \multicolumn{3}{|l|}{ Acquired heart disease $(n=4)$} \\
\hline Osteosarcoma & 1 & \\
\hline Myocarditis & 1 & \\
\hline Complete heart block & 1 & \\
\hline Kawasaki disease & 1 & \\
\hline
\end{tabular}

independent observer who was unaware of stethoscope results, using a semiautomatic edge-detection computer program on images obtained in the left anterior oblique projection which provided optimal separation of the atria and ventricles. Regional wall motion abnormalities were analyzed using cinematic closed-loop display. In 3 of the 4 patients studied by gated blood pool scintigraphy, studies were performed within 1 hour of the stethoscope study; in 1 patient the scintigraphic scan was performed 3 weeks after the nuclear stethoscope study.

Cineangiography: LV cineangiograms were obtained using 1 to $1.5 \mathrm{ml} / \mathrm{kg}$ body weight of diatrizoate meglumine (Renovist II ${ }^{\circledR}$, Squibb) injected within 1 second. LVEF was measured using the area-length method ${ }^{12}$ on digitized biplane (anteroposterior/lateral or anteroposterior/left anterior oblique) views of the heart. Measurements were made by independent observers not involved in the study, who had no knowledge of stethoscope study results. Stethoscope studies were performed 30 minutes or more after $(n=16)$ or immediately before $(n=3) L V$ angiography.

Comparison of the ejection fraction determined by the nuclear stethoscope with that determined by cineangiography and scintigraphy was made using standard linear regression analysis, correlation coefficient and paired $t$ test. Group data are presented as mean \pm standard deviation. Statistical significance is at the $\mathrm{p}<0.05$ level.

\section{Results}

LVEF measured by cineangiography in 19 patients ranged from 20 to $80 \%$ (mean $59 \pm 12$ ) and in the 4 patients studied by scintigraphy from 30 to $89 \%$ (mean 58 \pm 21 ). EF determined by the nuclear stethoscope in the same 23 patients ranged from 18 to $79 \%$ (mean $54 \pm$ $16 \%$ ) (difference not significant). There was a direct relationship between LVEF determined by the nuclear stethoscope and cineangiography or scintigraphy $(r=$ $0.869 ; \mathrm{p}<0.001$ ) (Fig. 1).

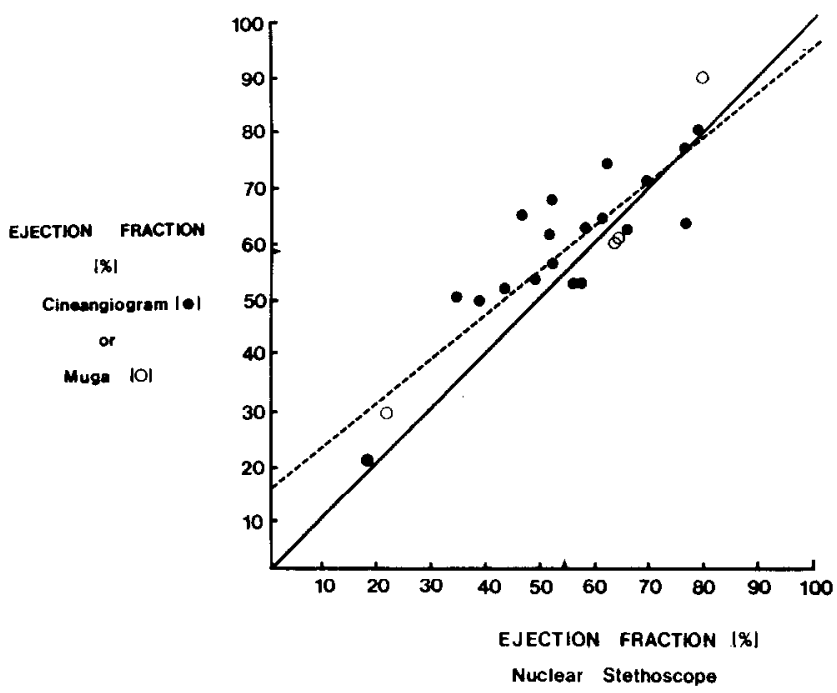

FIGURE 1. Comparison of left ventricular injection fraction determined by the nuclear stethoscope and by cineangiography or gated blood pool scintigraphy (Muga) in 23 pediatric patients $(y=0.78 x+16.6 ; r=$ $0.869 ; p<0.001 ; n=23$ ).

In the 12 patients $>5$ years of age, whose body surface areas ranged from 1 to $1.83 \mathrm{~m}^{2}$ (mean 1.42), the EF measured by stethoscope correlated more closely to cineangiography or scintigraphy (Fig. 2) than in younger patients (Fig. 3). In children younger than 5 years (BSA 0.23 to $0.74 \mathrm{~m}^{2} ;$ mean $0.43 \mathrm{~m}^{2}$ ) the EF measured by the nuclear stethoscope underestimated the values obtained by angiography (Fig. 3). However, the difference in mean EF calculated in these patients $(53 \pm 12 \%$ vs 58 $\pm 7 \%$ ) was not statistically significant.

\section{Discussion}

The present study demonstrates that the nuclear stethoscope can accurately estimate LVEF in the pediatric population. The stethoscope values correlate well with both cineangiogram and gated blood pool studies over a wide range of ejection fractions. The data are in agreement with previous studies reported in adults. 7,9 However, EF values measured by the nuclear stethoscope are not as accurate in smaller children. The explanation for this disparity may lie in the size of the collimator, which is designed for adults. If the field of view of the collimator is too large for the relatively small size of the pediatric heart, an overestimation of systolic and, to a lesser degree, diastolic counts will be made, resulting in underestimation of the "real" EF. ${ }^{7}$ Although decreasing collimator diameter could result in an appropriately limited LV field of view, the very small chamber volume will limit the count rate response of the probe. ${ }^{8}$ Patient cooperation, which might be expected to be less in younger patients, was not a factor in that it did not adversely influence the measurements in our study. All patients younger than 5 years of age were studied after being sedated for cardiac catheterization. Alterations in the LV field of view occurring with respiratory motion ${ }^{7}$ were not observed in our patients at 


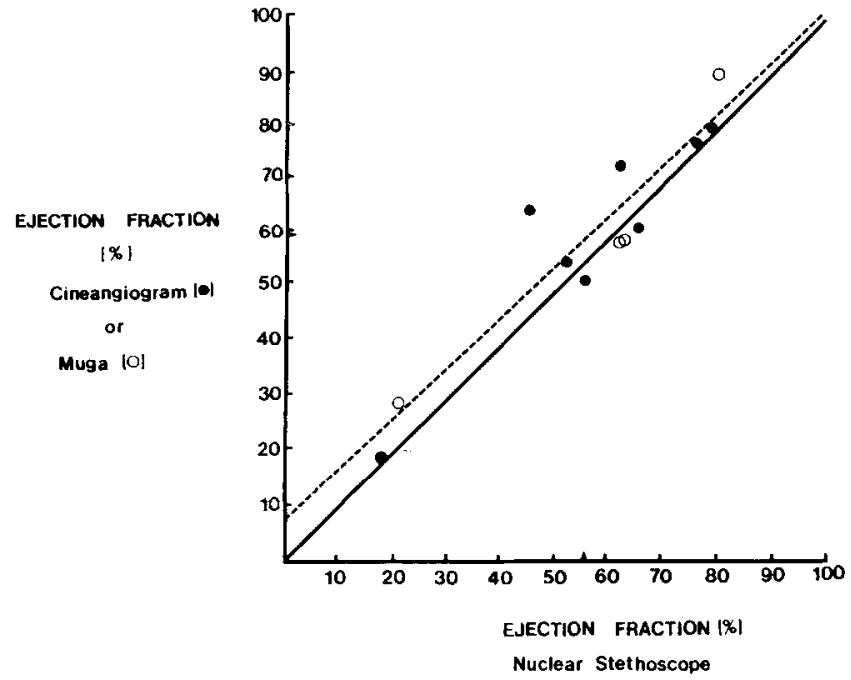

FIGURE 2. Comparison of left ventricular ejection fraction determined by the nuclear stethoscope and by cineangiography or gated blood pool scintigraphy (Muga) in 12 patients older than 5 years $(y=0.92 x+8.2$; $r=0.926 ; p<0.001 ; n=12)$.

rest. Although wall motion abnormalities may cause erroneous stethoscope values, ${ }^{10}$ none of our patients demonstrated wall motion abnormalities detectable by cineangiographic or gated blood pool studies. None of our patients had an abnormal spatial configuration of the left ventricle (dextrocardia, L-looping of ventricles), which may result in difficulty in identifying LV activity.

In addition to potential sources of error in stethoscope studies, a further concern is the time involved in performing the examination. Whereas the red cell labeling technique is identical to that used in standard blood pool studies, the computer-assisted algorithms for determining optimal ventricular and background counts are tedious and time consuming. Small changes in probe position relative to the chest wall and heart can result in major alterations in total counts over the ventricle and background, altering results. Painstaking patience, deliberately slow movements and a nonhurried environment are critical for performing accurate studies. A good correlation has indeed been demonstrated between tests performed by 2 experienced operators. ${ }^{7}$

The nuclear stethoscope has several advantages over other methods of LV function analysis. The first is the relatively low cost of the stethoscope, especially compared with any angiographic or standard gamma camera equipment. Second, the camera can be easily transported to a clinic, intensive care unit or catheterization laboratory setting. Third, the ability of the stethoscope to monitor beat-to-beat function allows detection of rapidly changing hemodynamic events. The rapid determination and display of these events is useful in the evaluation of arrhythmias, ${ }^{11,13}$ and may be helpful in monitoring acute changes in LV function during pharmacologic intervention or cardiac pacing in critically ill or postoperative patients. Gated studies of LVEF can be obtained using the stethoscope and correlate well

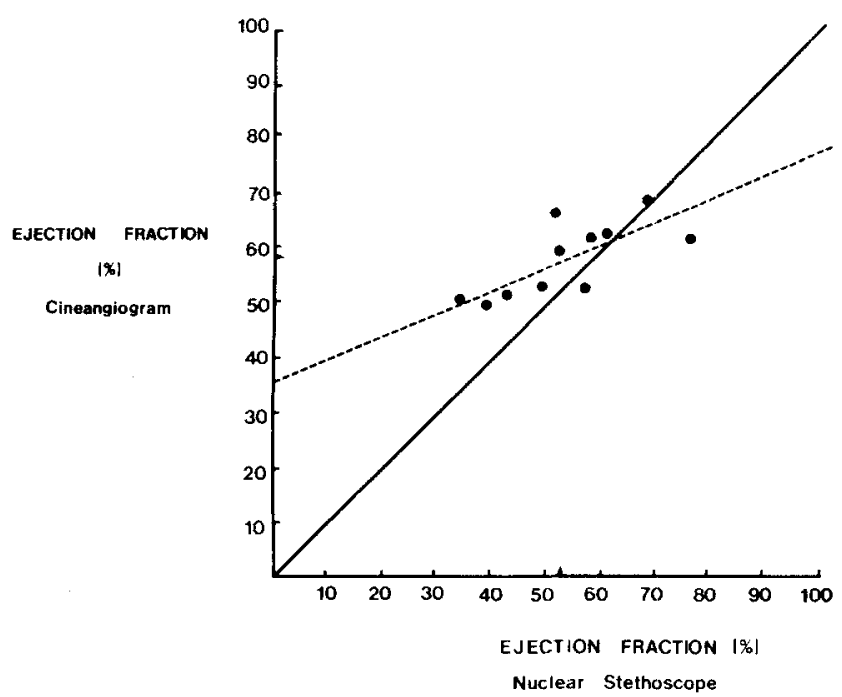

FIGURE 3. Comparison of left ventricular ejection fraction determined by the nuclear stethoscope and by cineangiography in 11 patients younger than 5 years $(y=0.41 x+36.6 ; r=0.728 ; p<0.02 ; n=$ 11).

with standard gamma camera techniques. ${ }^{10}$ Recent applications of the nuclear stethoscope in adults include diastolic function studies, ${ }^{14}$ pressure-volume analysis $^{15,16}$ and LV dysfunction in patients with coronary artery disease $e^{9}$ or adriamycin toxicity. ${ }^{17}$ The clinical usefulness of these applications in a pediatric population has not been explored.

Our results suggest that the nuclear stethoscope can be used to monitor resting LVEF in pediatric patients. Problems with operator expertise, motion artifact and patient size appear to limit advances with the present device. Modifications in the instrument, use of different isotopes and further clinical investigations are required before this device can be considered a standard tool for pediatric cardiologists.

Acknowledgment: We greatly appreciate the help of Diana Kuhl and Sandy Suter in preparing the manuscript.

\section{References}

1. Parrish MD, Graham TP, Born ML, Jones J. Radionuclide evaluation of right and left ventricular function in children: validation of methodology. Am J Cardiol 1982;49:1241-1247.

2. Treves S, Collins-Nakai RL. Radioactive tracers in congenital heart disease Am J Cardiol 1976;38:711-721.

3. Kurtz D, Ahnberg DS, Freed M, Lafarge CG, Treves S. Quantitative raKurtz D, Ahnberg DS, Freed M, Lafarge CG, Ireves S. Quantitative ra-
dionuclide angiocardiography-determination of left ventricular ejection dionuclide angiocardiography-determination of
fraction in children. Br Heart $\mathrm{J} 1976 ; 38: 966-973$.

4. Kriss JP, Enright LP, Hayden WG, Wexler L, Shumway NE. Radioisotopic angiocardiography: findings in congenital heart disease. I Nucl Med 1972;13:31: -40 .

5. Reduto LA, Berger HJ, Johnstone DE, Hellenbrand W, Wackers FJ, Whittemore B, Cohen LS, Gottschalk A, Zaret BL. Radionuclide assessment of right and left ventricular exercise reserve after total correction of tetralogy of Fallot. Am J Cardiol 1980;45:1013-1018.

6. Wagner HN, Wake R, Mickoloff E, Natarajan TK. The nuclear stethoscope: a simple device for generation of left ventricular volume curves. Am J a simple device for generatio
Cardiol 1976;38:747-750.

7. Berger HJ, Davies RA, Batsford WP, Hoffer PB, Gottschalk A, Zaret BL. Beat-to-beat left ventricular performance assessed from the equilibrium cardiac blood pool using a computerized nuclear probe. Circulation 1981;63:133-142.

8. Bacharach SL, Green MV, Borer JS, Ostrow HG, Redwood DR, Johnston GS. ECG-gated scintillation probe measurement of left ventricular function. 
J Nucl Med 1977:18:1176-1183

9. Wagner HN, Rigo P, Baxter RH, Alderson PO, Douglass KH, Housholder DF. Monitoring ventricular function at rest and during exercise with a nonimaging nuclear detector. Am J Cardiol 1979;43:975-979.

10. Strashun A, Horowitz SF, Goldsmith SJ, Teichholz LE, Dicker A, Micel K, Gorlin A. Noninvasive detection of left ventricular dysfunction with a K, Gorlin A. Noninvasive detection of left ventricular dysfunction with a
portable electrocardiographic gated scintillation probe device. Am J Cardiol 1981;47:610-617.

11. Camargo EE, Harrison KS, Wagner HN, Bourguignon MH, Reld PR, Alderson PO, Baxter RH. Noninvasive beat-to-beat monitoring of left ventricular function by a non-imaging nuclear detector during premature ventricular contractions. Am $\mathrm{J}$ Cardiol 1980;45:1219-1224.

12. Graham TP, Jarmakani JM, Canent RV, Morrow MN. Left heart volume estimation in infancy and childhood: reevaluation of methodology and normal estimation in infancy and childhood: reevalu
values. Circulation 1971;43:895-904.

13. Schneider J. Berger HJ, Sands JM Lachman AB, Zaret BL. Beat-to-beat left ventricular performance in atrial fibrillation: radionuclide assessment with the computerized nuclear probe. Am J Cardiol 1983:51:11891195.

14. Bonow RO, Ostrow HG, Rosing DR, Lipson LC, Kent KM, Allen SI, Bacharach SL, Green MV, Epstein SE. Scintillation probe measurement of left ventricular diastolic function: effect of verapamil in hypertrophic cardiomyopathy (abstr). Circulation 1981;64:suppl IV:IV -35

15. Berger H, Byrd W, Giles R, Orphanoudakis S, Langou R, Zaret B. Auto mated beat-to-beat left ventricular pressure-volume and volume analysis in man with the computerized nuclear probe (astr). Circulation 1981;64:supp IV:IV-243

16. Berger H, Byrd W, Giles R, Orphanoudakls S, Zaret B. Beat-to-beat left ventricular pressure-volume relationships assessed from the equilibrium cardiac blood pool using the computerized nuclear probe (abstr). J Nucl Med 1982;23:47.

17. Strashun A, Horowitz SF, Goldsmith SJ. Can the nuclear stethoscope replace gated blood pool imaging for the detection of adriamycin toxicity? (abstr). Circulation 1982;66:suppl II: :I-124. 